\title{
The pattern of Electrophysiological Abnormality in Long-Standing Type-2 Diabetes Mellitus Patients: Experience at Referral Neurology Hospital in Bangladesh
}

\author{
Bithi Debnath', Md. Enayet Hussain², AFM Al Masum Khan³, Md. Ferdous Mian4, Md. Nahidul Islam5, \\ Md Badrul Alam ${ }^{6}$, Quazi Deen Mohammad', Rajib Nayan Chowdhury ${ }^{8}$ \\ ${ }^{1}$ Assistant Professor, Department of Pediatric Neurology, National Institute of Neurosciences and Hospital, Dhaka, Bangladesh; ${ }^{2}$ Associate \\ Professor, Department of Neurology, National Institute of Neurosciences and Hospital, Dhaka, Bangladesh; ${ }^{3}$ Assistant Professor, \\ Department of Neurology, National Institute of Neurosciences and Hospital, Dhaka, Bangladesh; ${ }^{4}$ Assistant Professor, Department of \\ Neurology, National Institute of Neurosciences and Hospital, Dhaka, Bangladesh; ${ }^{5}$ Assistant Professor, Department of Neurology, \\ National Institute of Neurosciences and Hospital, Dhaka, Bangladesh; ${ }^{6}$ Professor and Joint Director, Department of Neurology, \\ National Institute of Neurosciences and Hospital, Dhaka, Bangladesh; ${ }^{7}$ Professor and Head, Department of Neurology, \\ National Institute of Neurosciences and Hospital, Dhaka, Bangladesh; 8Associate Professor and Head, Department of \\ Neurophysiology, National Institute of Neurosciences and Hospital, Dhaka, Bangladesh
}

[Received on: 22 November 2020; Accepted on: 12 December 2020; Published: 1 January 2021]

\begin{abstract}
Background: Nerve conduction studies (NCS) are the most objective measure of nerve function, and their use is recommended in the clinical and epidemiological evaluation of diabetic polyneuropathy. Objective: This study was conducted to describe the pattern of electrophysiological abnormality in long-standing type-2 Diabetes Mellitus patients. Methodology: This cross-sectional study was conducted in the Department of Neurophysiology at the National Institute of Neurosciences \& Hospital, Dhaka, Bangladesh from July 2017 to June 2019. Among the one hundred and eight consecutive patients of type 2 diabetes with a duration of more than 10 years attending the Neurophysiology laboratory, patients were selected for the study based on the inclusion and exclusion criteria. NCS study of the right upper limb (median and ulnar nerves) and left lower limbs (tibial, peroneal, and sural nerves) were done. NCS of other nerves were also done when indicated. Result: A total number of 92 patients were recruited for this study. NCS was abnormal in 56 $(60.9 \%)$ patients. $43.5 \%(\mathrm{n}=40)$ patients were male and $56.5 \%(\mathrm{n}=52)$ patient were female. Among the 56 $(60.9 \%)$ patients with abnormal NCS, most [35 (38\%)] had mixed types (both sensory and motor) of neuropathy. In $28(30.4 \%)$ patients, both demyelination and axonal involvement were present. The median nerve $(46.7 \%)$ was the commonest nerve to be involved followed by the Sural nerve. In patients with elevated $\mathrm{HbA} 1 \mathrm{C}$, the axonal loss was more pronounced in the lower limbs' nerves. Polyneuropathy (28.26\%) was more than mononeuropathy $(21.74 \%)$. Conclusion: Most of the patients of type 2 long-standing DM developed a mixed type of polyneuropathy and elevated $\mathrm{HbA1C}$ was significantly associated with the axonal involvement predominantly in lower limbs' nerves. [Journal of National Institute of Neurosciences Bangladesh, January 2021;7(1): 10-13]
\end{abstract}

Keywords: Nerve conduction study, Type 2 Diabetes Mellitus, HbA1C, Polyneuropathy

Correspondence: Dr. Bithi Debnath, Assistant Professor, Dept. of Pediatric Neurology, National Institute of Neurosciences and Hospital, Sher-e-Bangla Nagar, Dhaka-1207, Bangladesh; Cell no.: +8801711236107; Email: bithidebnath@gmail.com

Conflict of interest: There is no conflict of interest relevant to this paper to disclose.

Funding agency: This research project was not funded by any group or any institution.

Contribution to authors: BD, MEH, AFMAMK were involved in study designing, data collection, compiling, data analysis, and manuscript writing. Rests were involved in overall supervision.

How to cite this article: Debnath B, Hussain ME, Khan AFMAM, Mian MF, Islam MN, Alam MB, $\neg$ Mohammad QD, Chowdhury RN. The pattern of Electrophysiological Abnormality in Long-Standing Type-2 Diabetes Mellitus patients: Experience at Referral Neurology Hospital in Bangladesh. J Natl Inst Neurosci Bangladesh, 2021;7(1): 10-13

Copyright: (C2021. Debnath et al. Published by Journal of National Institute of Neurosciences Bangladesh. This article is published under the Creative Commons CC BY-NC License (https://creativecommons.org/licenses/by-nc/4.0/). This license permits use, distribution, and reproduction in any medium, provided the original work is properly cited and is not used for commercial purposes.

\section{Introduction}

Diabetes mellitus (DM) is considered as a group of disorders of heterogeneous etiology, characterized by chronic hyperglycemia and other metabolic abnormalities caused by defects in insulin secretion, insulin action, or both ${ }^{1}$. The longer the duration of 
diabetes, the higher is the risk of microvascular like retinopathy, nephropathy, and neuropathy, and macrovascular complications (arteriosclerosis) ${ }^{2}$. Neuropathy is one of the earliest and most common chronic complications of diabetes. Among all the diabetic neuropathies diabetic sensorimotor polyneuropathy (DSPN) is the commonest type affecting approximately $30.0 \%$ in hospitalized diabetes patients and $20.0 \%$ in community-based patients ${ }^{3}$.

Nerve conduction studies (NCS) are the most objective measure of nerve function, and their use is recommended in the clinical and epidemiological evaluation of diabetic polyneuropathy $(\mathrm{DPN})^{4}$. In clinical practice, however, NCS should not be considered a substitute for careful clinical examination. In the case of length-dependent diabetic neuropathy (LDDP), as in all small-fiber polyneuropathies, the main drawback of NCS is that small myelinated and unmyelinated nerve fibers, which are affected early in the disease course of diabetic neuropathy, do not contribute to the sensory action potential detected by routine NCS. The sensory action potential is altered only after the involvement of larger myelinated fibers, which is often a late event in patients with diabetes. Electrophysiological data must, therefore, always be evaluated in a clinical context ${ }^{5}$. This study was conducted to describe the pattern of electrophysiological abnormality in long-standing type-2 Diabetes Mellitus patients.

\section{Methodology}

This cross-sectional study was conducted in the Department of Neurophysiology at the National Institute of Neurosciences and Hospital, Dhaka, Bangladesh. One hundred and eight consecutive patients of type 2 diabetes with a duration of more than 10 years attending the Neurophysiology lab of the Hospital from July 2017 to June 2019 were selected for the study after obtaining their consent. Patients suffering from other comorbidities like hypothyroidism, vasculitis, nutritional deficiency, chronic inflammatory demyelinating polyneuropathy, malignancy, and chemotherapy were excluded from the study. Their demographic profiles were noted and $\mathrm{HbAlC}$ level was measured. Ninety-two (92) patients were finally selected for the study, based on the inclusion and exclusion criteria. NCS study of the right upper limb (median and ulnar nerves) and left lower limbs like tibial, peroneal, and sural nerves were done using the Neuropath S1 machine by Nihon Kohden. Latency, amplitude, and nerve conduction velocity were assessed. $\mathrm{P}$ values $<0.05$ were taken as the level of significance.

\section{Results}

The study included 92 diabetic patients with a duration longer than 10 years. Among those, NCS was found to be abnormal in $56(60.9 \%)$ patients. The baseline characteristics of patients with normal and abnormal NCS were compared. Among the studied population, $43.5 \%(n=40)$ patients were male and $56.5 \%(n=52)$ patient were female. The mean age of the patients in both groups was almost equal (55.64 vs 56.52). No statistical significance was found between the two groups except the duration of diabetes which correlated significantly with abnormal NCS findings $(p<0.05)$ (Table 1).

Among the 56 (60.9\%) patients with abnormal NCS, 35 (38\%) had mixed type (both sensory and motor) of

Table 1: Baseline Characteristics of Studied Population $(\mathrm{n}=92)$

\begin{tabular}{|c|c|c|c|}
\hline Variables & $\begin{array}{c}\text { Patient with } \\
\text { Normal NCS } \\
\text { Parameters } \\
(n=36) \\
\end{array}$ & $\begin{array}{c}\text { Patient with } \\
\text { Abnormal NCS } \\
\text { Parameters } \\
(n=56) \\
\end{array}$ & Pvalue \\
\hline Mean Age (year) & $55.64 \pm 8.28$ & $56.52 \pm 9.86$ & 0.656 \\
\hline \multicolumn{4}{|l|}{ Mean age of onset } \\
\hline of diabetes (year) & $41.72 \pm 11.05$ & $39.71 \pm 9.45$ & 0.35 \\
\hline $\begin{array}{l}\text { Duration of } \\
\text { diabetes(year) }\end{array}$ & $13.69 \pm 6.26$ & $16.70 \pm 7.03$ & 0.04 \\
\hline \multicolumn{4}{|l|}{ Gender } \\
\hline Male & $22(23.9 \%)$ & $18(19.6 \%)$ & 0.408 \\
\hline Female & $31(33.7 \%)$ & $21(22.8 \%)$ & \\
\hline Habitat & & Habitat & \\
\hline Rural & $6(6.5 \%)$ & $4(4.3 \%)$ & 0.575 \\
\hline Urban & $47(51.1 \%)$ & $35(39 \%)$ & \\
\hline Education & & Education & \\
\hline Primary & $11(12 \%)$ & $10(10.9 \%)$ & 0.75 \\
\hline Secondary & $18(19.6 \%)$ & $9(9.8 \%)$ & \\
\hline Higher secondary & $8(8.7 \%)$ & $5(5.4 \%)$ & \\
\hline Graduate & $11(12 \%)$ & $11(12 \%)$ & \\
\hline Postgraduate & $5(5.4 \%)$ & $4(4.3 \%)$ & \\
\hline \multicolumn{4}{|l|}{ Monthly Income } \\
\hline$<10000$ & $4(4.3 \%)$ & $2(2.2 \%)$ & 0.66 \\
\hline 10000-19999 & $7(7.6 \%)$ & $14(15.2 \%)$ & \\
\hline 20000-29999 & $11(12 \%)$ & $14(15.2 \%)$ & \\
\hline $30000-39999$ & $5(5.4 \%)$ & $7(7.6 \%)$ & \\
\hline $40000-49999$ & $5(5.4 \%)$ & $9(9.8 \%)$ & \\
\hline$\geq 50000$ & $4(4.3 \%)$ & $10(10.9 \%)$ & \\
\hline \multicolumn{4}{|l|}{ Family of Diabetes } \\
\hline Yes & $24(26.1 \%)$ & $41(44.6 \%)$ & 0.32 \\
\hline No & $12(13 \%)$ & $15(16.3 \%)$ & \\
\hline
\end{tabular}


neuropathy, 15 (16.3\%) had only sensory neuropathy and $6(6.5 \%)$ had only motor neuropathy. Neuropathy was of mixed type (both demyelinating and axonal) in $28(30.4 \%)$, only demyelinating type in $22(23.9 \%)$, and only axonal in $6(6.5 \%)$ patients. The median nerve $(46.7 \%)$ was the commonest nerve to be involved followed by sural $(32.6 \%)$ and peroneal $(22.8 \%)$ nerves (Table 2).

Table 2: Pattern of Nerve Involvement in Nerve Conduction Study

\begin{tabular}{lcc}
\hline Variables & Frequency & Percent \\
\hline NCS Findings & 36 & 39.1 \\
Normal & 56 & 60.9 \\
Abnormal & & \\
Fibers Involved & 6 & 6.5 \\
Motor & 15 & 16.3 \\
Sensory & 35 & 38 \\
Mixed & & \\
Pathology of Nerve Involvement & 22 & 23.9 \\
Demyelinating & 6 & 6.5 \\
Axonal & 28 & 30.4 \\
Mixed & & \\
Nerves Involved & 43 & 46.7 \\
Median & 20 & 21.7 \\
Ulnar & 15 & 16.3 \\
Tibial & 21 & 22.8 \\
Peroneal & 30 & 32.6 \\
Sural & & \\
\hline
\end{tabular}

Table 3: Comparison of Nerve Conduction Parameters of the Studied Population with Normal and Elevated HbA1C Level

\begin{tabular}{lccc}
\hline Variables & $\begin{array}{c}\text { DM with elevated } \\
\text { HbA1C }(\mathbf{n}=\mathbf{6 2})\end{array}$ & $\begin{array}{c}\text { HbA1C }(\mathbf{n}=\mathbf{3 0}) \\
\text { value }\end{array}$ \\
\hline Median Nerve & & & \\
DL(ms) & $4.26 \pm 1.36$ & $3.94 \pm 1.16$ & 0.27 \\
CMAP amplitude $(\mathrm{mV})$ & $10.08 \pm 2.76$ & $11.06 \pm 3.13$ & 0.134 \\
CV(m/s) & $55.30 \pm 6.18$ & $54.39 \pm 11.29$ & 0.61 \\
SNAP latency $(\mathrm{ms})$ & $3.52 \pm 2.23$ & $2.69 \pm 0.95$ & $\mathbf{0 . 0 5}$ \\
SNAP amplitude $(\mu \mathrm{V})$ & $23.24 \pm 13.43$ & $28.93 \pm 5.51$ & 0.74 \\
Ulnar Nerve & & & \\
DL(ms) & $2.60 \pm 0.40$ & $2.52 \pm 0.54$ & 0.43 \\
CMAP amplitude $(\mathrm{mV})$ & $8.76 \pm 1.96$ & $9.01 \pm 2.34$ & 0.58 \\
CV(m/s) & $57.0 \pm 7.38$ & $58.81 \pm 6.23$ & 0.25 \\
SNAP latency $(\mathrm{ms})$ & $2.13 \pm 0.66$ & $2.24 \pm 0.41$ & 0.39 \\
SNAP amplitude $(\mu \mathrm{V})$ & $25.08 \pm 12.86$ & $26.92 \pm 10.47$ & 0.49 \\
Tibial Nerve & & & \\
DL(ms) & $3.92 \pm 0.75$ & $3.66 \pm 0.81$ & $\mathbf{0 . 1 2}$ \\
CMAP amplitude $(\mathrm{mV})$ & $8.89 \pm 4.32$ & $10.29 \pm 4.34$ & 0.14 \\
CV(m/s) & $40.53 \pm 11.82$ & $46.39 \pm 6.05$ & 0.012 \\
Peroneal Nerve & & & \\
DL(ms) & $4.23 \pm 2.09$ & $3.29 \pm 1.06$ & $\mathbf{0 . 0 2 3}$ \\
CMAP amplitude $(\mathrm{mV})$ & $3.26 \pm 2.12$ & $4.63 \pm 3.09$ & $\mathbf{0 . 0 1 5}$ \\
CV(m/s) & $39.76 \pm 11.19$ & $41.71 \pm 15.41$ & 0.49 \\
Sural Nerve & & & \\
SNAP latency $(\mathrm{ms})$ & $2.43 \pm 1.78$ & $1.89 \pm 0.78$ & $\mathbf{0 . 0 1}$ \\
SNAP amplitude $(\mu \mathrm{V})$ & $8.68 \pm 8.11$ & $13.06 \pm 7.34$ & $\mathbf{0 . 0 1 4}$ \\
\hline
\end{tabular}

Based on the level of $\mathrm{HbA1C}$, patients were grouped into DM with elevated (HbAlc $>7 \%)$ and DM with normal $\mathrm{HbA} 1 \mathrm{C}(\mathrm{HbAlc}<7 \%)$ to search for the effects of chronic hyperglycemia on different nerves. 62 (67.39\%) patients had elevated HbA1c. The parameters of NCS which turned out significant in comparison of the two groups were prolonged sensory latency in median nerves, reduced conduction velocity in tibial nerve, prolonged distal motor latency with reduced CMAP amplitude in the common peroneal nerve, prolonged SNAP latency with reduced amplitude in the sural nerve. Actually, in some, there was evidence of demyelination, in some axonal loss, and in some both although no specific pattern was seen (Table 3).

Among the patients with abnormal NCS (60.9\%), the majority (28.26\%) had polyneuropathy (PN), 21.74\% had carpal tunnel syndrome (CTS), 7.61\% cases had both PN and CTS (Figure I).

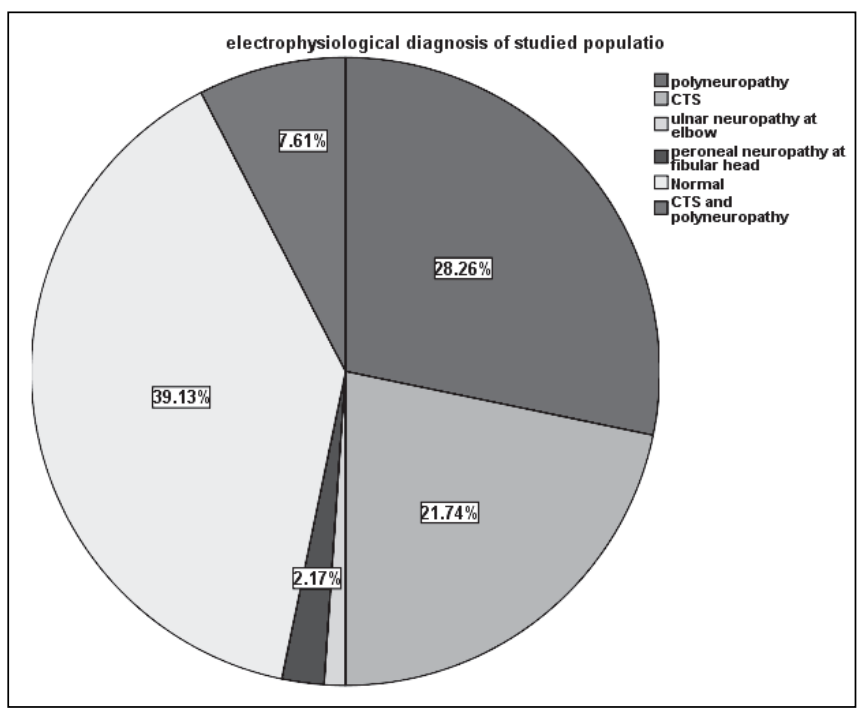

Figure I: Electrophysiological Diagnosis of Studied Population

\section{Discussion}

This study revealed that the nerve abnormalities were more common in those with a longer duration of diabetes i.e. the longer the duration of diabetes the higher is the chance of the nerves being affected. Khawaja $\mathrm{N}$ et $\mathrm{al}^{6}$ described that diabetes duration was the strongest predictor for DPN; compared to patients with T2DM for less than 5 years, those with diabetes duration for $5-11$ years $(\mathrm{OR}=5.25)$ and $\geq 12$ years $(\mathrm{OR}=16.98)$ were more likely to have DPN $(\mathrm{p}<$ 0.001 ). In another study, a lower prevalence of polyneuropathy was found in patients with a duration of DM less than 5 years and highest in those with a duration of DM more than 15 years $^{7}$. The association 
between the duration of diabetes mellitus and neuropathy was also evident in a research study on the epidemiology of diabetic complications ${ }^{8}$. The presence of diabetic neuropathy was significantly associated with higher HbAlc levels and the long duration of diabetes ${ }^{9}$. A long duration of diabetes and poor glycemic control is associated with increased production of glycosylation end products, metabolic derangements, endothelial injury, and oxidative products $^{10-11}$.

The study also revealed that among the $56(60.9 \%)$ patients with abnormal NCS, most [35 (38\%)] had mixed type of neuropathy (both sensory and motor), 15 $(16.3 \%)$ had only sensory neuropathy and $6(6.5 \%)$ cases had only motor neuropathy. Mohan et $\mathrm{a}^{12}$ in their study from Punjab found a similar result, sensory-motor polyneuropathy being the most common type followed by pure sensory and pure motor neuropathy. A study in children of type $1 \mathrm{DM}$ patients found sensorimotor neuropathy as the most prevalent type followed by motor and the least was sensory neuropathy ${ }^{13}$.

In most of the cases, both myelin and axons were involved which is a mixed pattern of neuropathy followed by only demyelinating in 22(23.9\%)] patients and only axonal in $6(6.5 \%)$ patients. Similar findings were found in other studies ${ }^{14}$. The most common nerve affected was the median nerve followed by the sural nerve.

The parameters of NCS which turned out significant in comparison of the two groups are- prolonged sensory latency in the median nerves, reduced conduction velocity in the tibial nerve, prolonged distal motor latency with reduced CMAP amplitude in the common peroneal nerve, prolonged SNAP latency with reduced amplitude in the sural nerve. Most of the lower limb nerves showed axonal involvement with some showing mixed pattern while the upper limb nerves predominantly showed demyelinating changes. A similar electrophysiological pattern of involvement of the nerves was also reported in a previous study ${ }^{15}$. Among the patients with abnormal NCS (69.1\%), the majority $(28.26 \%)$ had polyneuropathy (PN), 21.74\% cases had carpal tunnel syndrome (CTS), 7.61\% had both PN and CTS.

\section{Conclusion}

The higher the duration of diabetes the more is the chance of the nerves being affected. In most patients, both sensory and motor fibers are involved. There is demyelination as well as axonal involvement. The median nerve is the most common to be involved followed by sural nerves. In the lower limbs, the axonal loss was more pronounced. Most had polyneuropathy, few mononeuropathies, and in many both.

\section{References}

1. Kuzuya T, Nakagawa S, Satoh J, et al. Report of the committee on the classification and diagnostic criteria of diabetes mellitus. Diabetes Research and Clinical Practice, 2002;55(1):65-85

2. Papanas N, Ziegler D. Risk Factors and Comorbidities in Diabetic Neuropathy: An Update 2015. Rev Diabet Stud 2015; 12(1-2):48-62

3. Ziegler D, Papanas N, Vinik AI, Shaw JE. Epidemiology of polyneuropathy in diabetes and prediabetes. Handb Clin Neurol. 2014;126:3-22

4. Vinik AI, Kong X, Megerian JT, Gozani SN. Diabetic nerve conduction abnormalities in the primary care setting. Diabetes Technol Ther. 2006;8(6):654-62.

5. Said G. Diabetic Neuropathy--A Review. Nat Clin Pract Neurol. 2007;3(6):331-340.

6. Khawaja N, Abu-Shennar J, Saleh M, Dahbour SS, Khader YS, Ajlouni KM. The prevalence and risk factors of peripheral neuropathy among patients with type 2 diabetes mellitus; the case of Jordan. Diabetology \& metabolic syndrome. 2018;10(1):1-0

7.Oguejiofor OC, Odenigbo CU, Oguejiofor CB. Evaluation of the effect of duration of diabetes mellituson peripheral neuropathy using the United Kingdom screening test scoringsystem, bio-thesiometry and aesthesiometry. Niger J Clin Pract 2010, 13:240-47

8. Shun CT, Chang YC, Wu HP, Hsieh SC, Lin WM, Lin YH, Tai TY, Hsieh ST. Skin denervation in type 2 diabetes: correlations with diabetic duration and functional impairments. Brain 2004,127:1593-605

9. Nisar MU, Asad A, Waqas A, Ali N, Nisar A, Qayyum MA, et al. Association of Diabetic Neuropathy with Duration of Type 2 Diabetes and Glycemic Control. Cureus. 2015;7(8):e302

10. Nishikawa T, Edelstein D, Du XL, Yamagishi S, Matsumura T, Kaneda Y, et al. Normalizing mitochondrial superoxideproduction blocks three pathways of hyperglycaemic damage. Nature. 2000, 404:787-790

11. Soulis T, Thallas V, Youssef S, Gilbert RE, McWilliam BG, Murray-McIntosh RP, et al. Advanced glycation end products and their receptors co-localise in rat organs susceptible to diabetic microvascular injury. Diabetologia. 1997, 40:619-28

12. Mohan G, Chandey M, Monga A, Dev P. Comparative study of detection of diabetic neuropathy by clinical and nerve conduction study in type 2 diabetes mellitus patients. Int $\mathrm{J} \mathrm{Adv}$ Med. 2018;5(2):380-383

13. Cenesiz F, Tur BS, Tezic T, Gurer Y. Nerve conduction in children suffering insulin dependent diabetes mellitus. Indian Journal of Pediatrics. 2003;70(12):945-951

14. Bhuyan AK, Appaiah S. Clinical and electrophysiological correlation of peripheral neuropathy in newly diagnosed type 2 diabetes mellitus. Int J Adv Med 2018;5(3):542-549

15. Islam MR, Rahman $T$, Habib R, Irfan SMR, Rahman $A$, Bhowmik NB, et al. Electrophysiological Patterns of Diabetic Polyneuropathy: Experience from a Tertiary Care Hospital of Bangladesh. BIRDEM Med J 2017;7(2):114-120. 